\title{
Electrochemical and Spectroscopic Studies of the Oxidation Mechanism of the Herbicide Propanil
}

\author{
E. M. Garrido,${ }^{\dagger}$ J. L. F. C. Lima,${ }^{\ddagger}$ C. Delerue-Matos,${ }^{\dagger}$ F. Borges $, *, \S$ \\ A. M. S. Silva, ${ }^{\perp}$ J. A. P. Piedade,,$"$ and A. M. Oliveira Brett" \\ CEQUP/Departamento de Engenharia Quimica, Instituto Superior de Engenharia do Porto, \\ Instituto Politécnico do Porto, 4200-485 Porto, Portugal; CEQUP/Departamento de Química \\ Física and CEQOFFUP/Departamento de Química Orgânica, Faculdade de Farmácia, \\ Universidade do Porto, 4050-047 Porto, Portugal; Departamento de Química, Universidade de Aveiro, \\ 3810-193 Aveiro, Portugal; and Departamento de Química, Faculdade de Ciências e Tecnologia, \\ Universidade de Coimbra, 3004-535 Coimbra, Portugal
}

\begin{abstract}
Electrochemical oxidation of propanil in deuterated solutions was studied by cyclic, differential pulse, and square wave voltammetry using a glassy carbon microelectrode. The oxidation of propanil in deuterated acid solutions occurs at the nitrogen atom of the amide at a potential of $+1.15 \mathrm{~V} \mathrm{vs} \mathrm{Ag} /$ $\mathrm{AgCl}$. It was also found that, under the experimental conditions used, protonation at the oxygen atom of propanil occurs, leading to the appearance of another species in solution which oxidizes at +0.60 $\mathrm{V}$. The anodic peak found at $+0.79 \mathrm{~V} v \mathrm{Ag} / \mathrm{AgCl}$ in deuterated basic solutions is related to the presence of an anionic species in which a negative charge is on the nitrogen atom. The electrochemical data were confirmed by the identification of all the species formed in acidic and basic deuterated solutions by means of NMR spectroscopy. The results are supported by electrochemical and spectroscopic studies of acetanilide in deuterated solutions.
\end{abstract}

KEYWORDS: Herbicides; propanil; acetanilide; deuterated solutions; oxidation mechanism; electrochemistry; spectroscopy; nuclear magnetic resonance

\section{INTRODUCTION}

Propanil [3,4-dichloropropionalide] is an anilide (Scheme 1) used as a post-emergence selective contact herbicide in a wide variety of economically important crops, including rice, cotton, potatoes, and corn, to control broad-leaved and grass weeds (1). It has a long lifetime in the environment, $\mathrm{DT}_{50} \gg 1$ year $(4<$ $\left.\mathrm{pH}<9,22^{\circ} \mathrm{C}\right)(2)$.

Earlier studies of the electrochemical behavior of propanil and related $N$-substituted amides (e.g., acetanilide) by cyclic, differential pulse, and square wave voltammetry were done using a glassy carbon electrode in Britton-Robinson electrolyte (3). From these studies, it was found that propanil, under the analytical conditions described, shows an oxidation peak at $+1.27 \mathrm{~V}$ vs $\mathrm{Ag} / \mathrm{AgCl}$ at $\mathrm{pH}$ 7.5. Acetanilide, an analogue of the herbicide (Scheme 1), exhibits an oxidation potential similar to that of propanil, $+1.24 \mathrm{~V}$ vs $\mathrm{Ag} / \mathrm{AgCl}$. Although electrochemical data for the studied compounds were obtained, no efforts were made to elucidate the oxidation mechanism or to identify the species formed in solution.

* To whom correspondence should be addressed. Prof. Fernanda Borges, Faculdade de Farmácia do Porto, R. Aníbal Cunha, 4050-047 Porto, Portugal. Phone: +351-22-2078952. Fax: +351-22-2003977. E-mail: fborges@ff.up.pt.

Instituto Politécnico do Porto.

$\doteqdot$ Departamento de Química Física, Universidade do Porto.

$\S$ Departamento de Química Orgânica, Universidade do Porto.

$\perp$ Universidade de Aveiro.

"Universidade de Coimbra.
Scheme 1. Structures of Propanil and Acetanilide<smiles>CCC(=O)Nc1ccc(Cl)c(Cl)c1</smiles>

Propanil<smiles>CC(=O)Nc1ccccc1</smiles>

Acetanilide
The mechanism of oxidation of pesticides is currently a hot topic of research because it could allow a better understanding of their oxidation degradation processes and metabolic pathways. Thus, it is important to get insight into the oxidation behavior of these types of herbicides, using combined electrochemical and spectroscopic data for the identification of the species present in solution.

In this work, a detailed electrochemical study of the oxidation mechanism of propanil is presented for deuterated solutions at a glassy carbon microelectrode by means of cyclic, differential pulse, and square wave voltammetry. To clarify the electrontransfer mechanism, and to identify the species formed, NMR studies of propanil in acidic or basic deuterated solutions were also performed.

\section{MATERIALS AND METHODS}

Reagents and Solutions. Propanil was from Riedel-de-Haen (Hanover, Germany). All reagents were analytical grade and used as received. $\mathrm{D}_{2} \mathrm{O}, \mathrm{DCl}\left(20 \%\right.$ deuterium chloride in $\left.\mathrm{D}_{2} \mathrm{O}\right), \mathrm{NaOD}(40 \%$ 
sodium deuteroxide in $\mathrm{D}_{2} \mathrm{O}$ ), and $\mathrm{CD}_{3} \mathrm{OD}$ were obtained from Merck (Darmstadt, Germany) and Sigma (Deisenhofen, Germany).

Preparation of Solutions for Electrochemistry. Propanil (44 mg) was dissolved in $1.23 \mathrm{~mL}$ of $\mathrm{CD}_{3} \mathrm{OD}$ and $0.77 \mathrm{~mL}$ of $\mathrm{D}_{2} \mathrm{O}$. The electrochemical experiments were performed with three $0.5-\mathrm{mL}$ portions of the herbicide solution placed separately into the electrochemical minicell. To the first $0.5-\mathrm{mL}$ portion, one drop of $\mathrm{DCl}$ was added; to the second, one drop of NaOD was added; and to the third, nothing was added. The same experimental procedure was used for acetanilide (20 mg).

Preparation of Solutions for NMR. Propanil (44 mg) was dissolved in $1.23 \mathrm{~mL}$ of $\mathrm{CD}_{3} \mathrm{OD}$. The solution was diluted with $\mathrm{D}_{2} \mathrm{O}$ to $2.00 \mathrm{~mL}$, and $0.5 \mathrm{~mL}$ of the resulting solution was placed into each of three NMR tubes. One drop of DCl was added to the first tube and one drop of $\mathrm{NaOD}$ to the second tube, whereas the third tube remained unaltered. The NMR spectra of these solutions were recorded immediately and 3 $\mathrm{h}$ after the addition of the reagents. The spectra of the solutions (acidic, basic, and neutral) were recorded at $303 \mathrm{~K}$ to avoid insolubility problems. The same experimental procedure was used for acetanilide (20 mg).

Apparatus. All electrochemical experiments were performed with a 10- $\mu \mathrm{m}$ glassy carbon microelectrode (EE017), a platinum wire counter microelectrode (EE011), and an $\mathrm{Ag} / \mathrm{AgCl}$ reference electrode (EE008) [Ag/ $\mathrm{AgCl}, \mathrm{KCl}$ (saturated) vs SCE is $-0.045 \mathrm{~V} \mathrm{(4)]} \mathrm{in} \mathrm{a} \mathrm{minielectro-}$ chemical cell (CL008) inside a Faraday cage, all from Cypress Systems (Lawrence, KS).

The electrodes were attached to an Autolab PSTAT 10 potentiostat/ galvanostat running with model GPES version 3 software, from EcoChemie (Utrecht, The Netherlands). The potential range studied was from +0.3 to $+1.5 \mathrm{~V}$. The glassy carbon working microelectrode was polished with $1-\mu \mathrm{m}$ diamond spray (Kemet, Kent, UK).

${ }^{13} \mathrm{C}$ NMR spectra were recorded on a Bruker AMX 300 spectrometer operating at $75.47 \mathrm{MHz}$. Chemical shifts are expressed as $\delta(\mathrm{ppm})$ values relative to tetramethylsilane (TMS) as internal reference, and coupling constants $(J)$ are given in hertz.

\section{RESULTS AND DISCUSSION}

The electrochemical behavior of propanil in aqueous buffered solutions was previously studied by cyclic, differential pulse, and square wave voltammetry with a glassy carbon electrode (3). It was found that the anodic peak at $+1.25 \mathrm{~V}$ vs $\mathrm{Ag} / \mathrm{AgCl}$ at $\mathrm{pH} 7.5$ could be related to an oxidation process occurring at the nitrogen atom.

To get insight into the oxidation mechanism of this herbicide, electrochemical and spectroscopic studies were performed. For an adequate correlation of the data obtained by both processes, it was found important to check the electrochemical behavior of propanil in deuterated solutions.

Electrochemical studies of the herbicide in acidic and basic deuterated solutions were performed with microelectrodes, since they allow determinations to be made without the need of supporting electrolyte. The cyclic voltammograms obtained are presented in Figures $\mathbf{1}$ and $\mathbf{2}$. The data allowed us to conclude that the oxidation process is irreversible and $\mathrm{pH}$ dependent, as found previously in the study with nondeuterated aqueous buffer solutions (3). The oxidation mechanism probably consists of an electrochemical step with further dimerization of the products, which could lead to adsorption phenomena on the electrode surface. The oxidation processes of propanil in the different media seem to be similar, although the relation $\operatorname{Ip}($ acid $) / I p$ (basic) is inverted (Figures 3 and 4).

Square-wave voltammetry data (Figure 3) obtained with a glassy carbon microelectrode allowed us to verify that oxidation occurs in $\mathrm{DCl}$ at $+1.15 \mathrm{~V}$ vs $\mathrm{Ag} / \mathrm{AgCl}$ (Figure 3a) and in $\mathrm{NaOD}$ at $+0.79 \mathrm{~V}$ vs $\mathrm{Ag} / \mathrm{AgCl}$ (Figure 3c). In $\mathrm{D}_{2} \mathrm{O}$ solutions, no oxidation peaks are observed (Figure 3b).

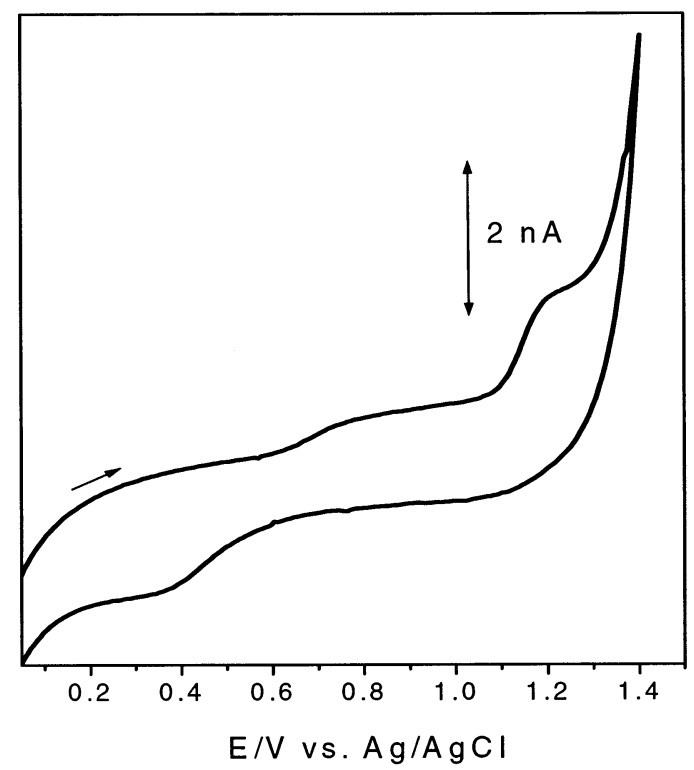

Figure 1. Cyclic voltammogram of a $7.6 \times 10^{-2} \mathrm{M}$ solution of propanil in DCl. Scan rate, $100 \mathrm{mV} \mathrm{s}^{-1}$.

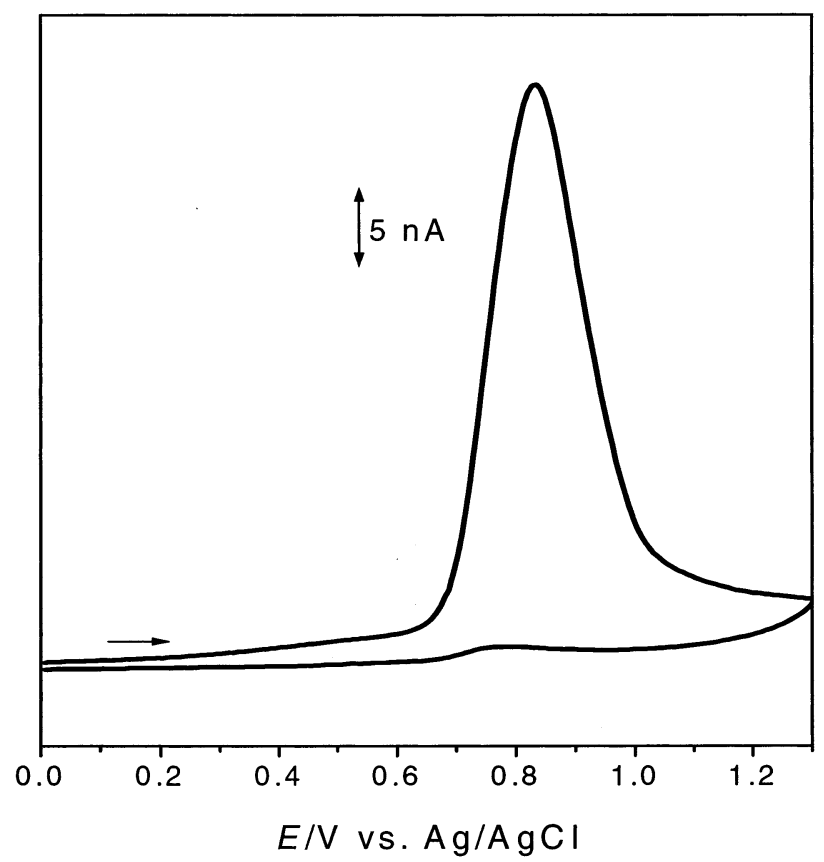

Figure 2. Cyclic voltammogram of a $7.6 \times 10^{-2} \mathrm{M}$ solution of propanil in $\mathrm{NaOD}$. Scan rate, $100 \mathrm{mV} \mathrm{s}^{-1}$.

NMR studies of deuterated solutions of propanil were conducted under neutral, acidic, and alkaline conditions. As one can see from the data shown in Table 1, ${ }^{13} \mathrm{C}$ NMR spectra of propanil in neutral and acidic conditions do not show significant differences (maximum $\Delta \delta=+0.1 \mathrm{ppm}$ ). These results indicate that, under these experimental conditions, there is no significant protonation of the amide group. If this situation had occurred, a deshielding of C-1, C-2, C-4, and C- 6 of the phenyl ring would be expected.

Under basic conditions, the presence of the negative charge on the amide nitrogen was confirmed by ${ }^{13} \mathrm{C}$ NMR spectroscopy of propanil. After amide deprotonation, there is a deshielding of C-1 $(\Delta \delta=+1.4 \mathrm{ppm}), \mathrm{C}-2(\Delta \delta=+0.4 \mathrm{ppm})$, and C-6 $(\Delta \delta$ $=+0.5 \mathrm{ppm})$ and a shielding of the carbon at the para position of the phenyl ring $(\mathrm{C}-4, \Delta \delta=-0.4 \mathrm{ppm})$ (Table 1). These shifts can be rationalized by considering the electronic effects 


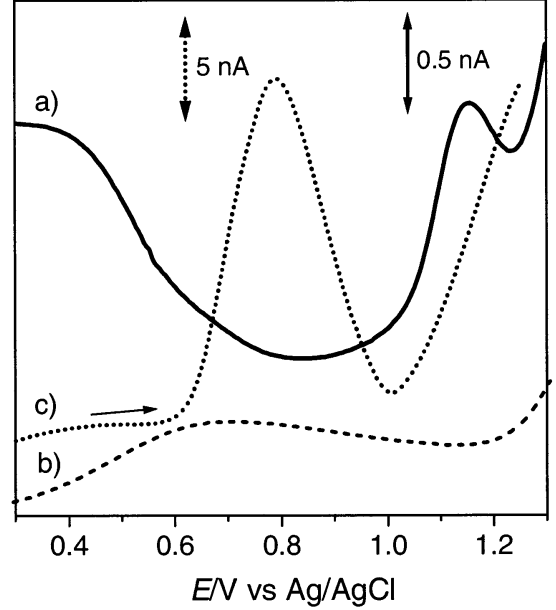

Figure 3. Square wave voltammograms of $7.6 \times 10^{-2} \mathrm{M}$ propanil in deuterated solutions: (a) $\mathrm{DCl}$, (b) $\mathrm{D}_{2} \mathrm{O}$, and (c) $\mathrm{NaOD}$. Frequency, 10 $\mathrm{Hz}$; scans increment, $5 \mathrm{mV}$; and amplitude, $50 \mathrm{mV}$.

Table 1. ${ }^{13} \mathrm{C}$ NMR Data of Propanil Deuterated Solutions

\begin{tabular}{|c|c|c|c|c|c|}
\hline carbons & $\begin{array}{c}\text { propanil } \\
\left(\mathrm{CD}_{3} \mathrm{OD}+\right. \\
\left.\mathrm{D}_{2} \mathrm{O}\right)\end{array}$ & $\begin{array}{c}\text { propanil } \\
\left(\mathrm{CD}_{3} \mathrm{OD}+\right. \\
\left.\mathrm{D}_{2} \mathrm{O}+\mathrm{DCl}\right)\end{array}$ & $\begin{array}{c}\Delta \delta \\
\mathrm{DCl}\end{array}$ & $\begin{array}{c}\text { propanil } \\
\left(\mathrm{CD}_{3} \mathrm{OD}+\right. \\
\left.\mathrm{D}_{2} \mathrm{O}+\mathrm{NaOD}\right)\end{array}$ & $\begin{array}{c}\Delta \delta \\
\mathrm{NaOD}^{b}\end{array}$ \\
\hline$C=0$ & 176.4 & 176.5 & +0.1 & 176.7 & +0.3 \\
\hline C-1 & 139.1 & 139.0 & -0.1 & 140.5 & +1.4 \\
\hline C-3 & 132.9 & 132.9 & 0.0 & 132.8 & -0.1 \\
\hline C-5 & 131.4 & 131.4 & 0.0 & 131.3 & -0.1 \\
\hline C-4 & 127.7 & 127.7 & 0.0 & 127.3 & -0.4 \\
\hline C-2 & 122.6 & 122.6 & 0.0 & 123.0 & +0.4 \\
\hline C-6 & 120.7 & 120.8 & 0.0 & 121.2 & +0.5 \\
\hline $\mathrm{CH}_{2} \mathrm{CH}_{3}$ & 30.9 & 30.9 & 0.0 & 31.2 & +0.3 \\
\hline $\mathrm{CH}_{3}$ & 10.1 & 10.1 & 0.0 & 10.4 & +0.3 \\
\hline
\end{tabular}

${ }^{a} \Delta \delta \mathrm{DCl}=\left(\delta \mathrm{CD}_{3} \mathrm{OD}+\mathrm{D}_{2} \mathrm{O}+\mathrm{DCl}\right)-\left(\delta \mathrm{CD}_{3} \mathrm{OD}+\mathrm{D}_{2} \mathrm{O}\right) \cdot{ }^{b} \Delta \delta \mathrm{NaOD}=$ $\left(\delta \mathrm{CD}_{3} \mathrm{OD}+\mathrm{D}_{2} \mathrm{O}+\mathrm{NaOD}\right)-\left(\delta \mathrm{CD}_{3} \mathrm{OD}+\mathrm{D}_{2} \mathrm{O}\right)$.

on the carbons of the phenyl ring due to the charge of the anion. Such shifts can be expected if a situation parallel to the phenolphenoxide case is considered; i.e., there will be a deshielding of the ipso and the ortho and a shielding of the para carbon atoms (5). The anionic charge on the nitrogen of the amide also causes a deshielding of the carbon atoms of the propanoyl group $(\Delta \delta=+0.3 \mathrm{ppm})$.

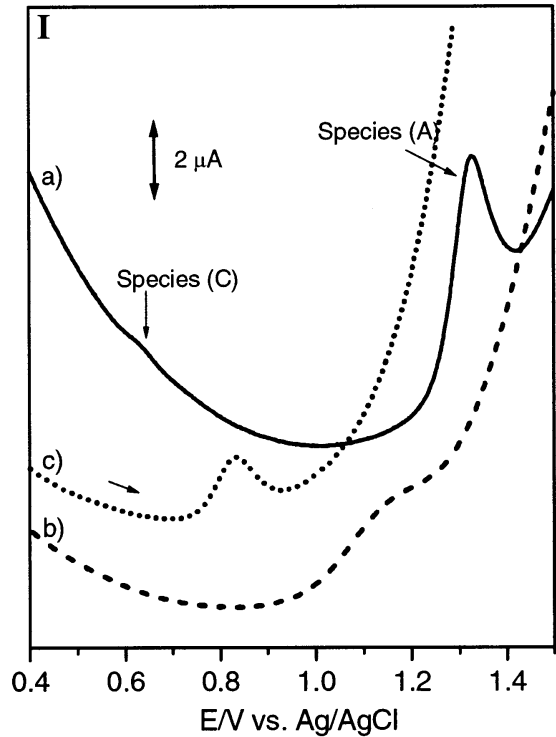

Scheme 2. Structures of the Chemical Species of $\mathrm{N}$-Phenylamides Found in $\mathrm{DCl}(\mathrm{A})$ and $\mathrm{NaOD}(\mathrm{B})$<smiles>[R3]C(=O)N([2H])c1ccc([R])c([R])c1</smiles>

(A)<smiles>[R]C(=O)Nc1ccc([R])c([R])c1</smiles>

(B)
$\mathrm{R}_{1}=\mathrm{R}_{2}=\mathrm{H} ; \mathrm{R}_{3}=\mathrm{CH}_{3}$ Acetanilide

$\mathrm{R}_{1}=\mathrm{R}_{2}=\mathrm{Cl} ; \mathrm{R}_{3}=\mathrm{CH}_{2} \mathrm{CH}_{3}$ Propanil

The NMR spectra were also recorded $3 \mathrm{~h}$ after sample preparation, and no changes were observed.

Through NMR analysis of the species found in deuterated solutions, it was proposed that, in acidic solution, the main species is neutral propanil (A), whereas in basic solution the anionic form (B) is present (Scheme 2).

If the results are compared with those obtained for the oxidation of propanil in aqueous buffer solutions (3), a shift of the oxidation potentials to less positive values is observed in deuterated solutions. The shift observed in acid media, of approximately $0.22 \mathrm{~V}$, cannot be explained only by the difference in the alcoholic content of the solutions. These results can only be interpreted if one takes into account that, under these experimental conditions, substitution of hydrogen by deuterium occurs at the $\mathrm{N}-\mathrm{H}$ bond. The presence of the deuterium atom can lead to an increase in the electron density at nitrogen due to the electron-donating inductive effect $(+I)$ of deuterium relative to hydrogen. Consequently, oxidation is facilitated, leading to a less positive oxidation potential $(6,7)$. In alkaline media, the shift can be explained on the basis of the high alcohol concentration of the solution.

Regarding the currents obtained in deuterated basic solutions, when compared with those observed in previous work (3), one can propose that the increase in current can be related to the presence of the species $\mathrm{OD}^{-}$, which is a stronger nucleophile in $\mathrm{D}_{2} \mathrm{O}$ than $\mathrm{OH}^{-}$in $\mathrm{H}_{2} \mathrm{O}(6,7)$.

In the differential pulse voltammetry study of propanil in deuterated acidic solutions, another small peak located at +0.60 $\mathrm{V}$ vs $\mathrm{Ag} / \mathrm{AgCl}$ was observed (Figure 4IIa). This peak was hardly noticeable in aqueous buffer (Figure 4Ia). To check if the occurrence of this peak is related to the use of deuterated

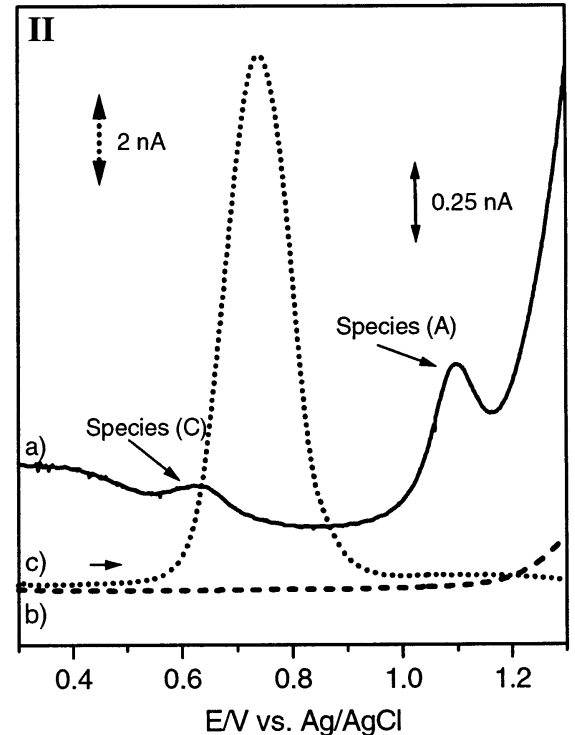

Figure 4. Differential pulse voltammograms of propanil: (l) $2.4 \times 10^{-4} \mathrm{M}$ in $0.3 \mathrm{M}$ Britton-Robinson buffer at (a) pH 1.9, (b) pH 7.0, and (c) pH 12.0; (II) $7.6 \times 10^{-2} \mathrm{M}$ in deuterated solutions (a) $\mathrm{DCl}$, (b) $\mathrm{D}_{2} \mathrm{O}$, and (c) $\mathrm{NaOD}$. Scan rate, $5 \mathrm{mV} \mathrm{s}^{-1}$. 


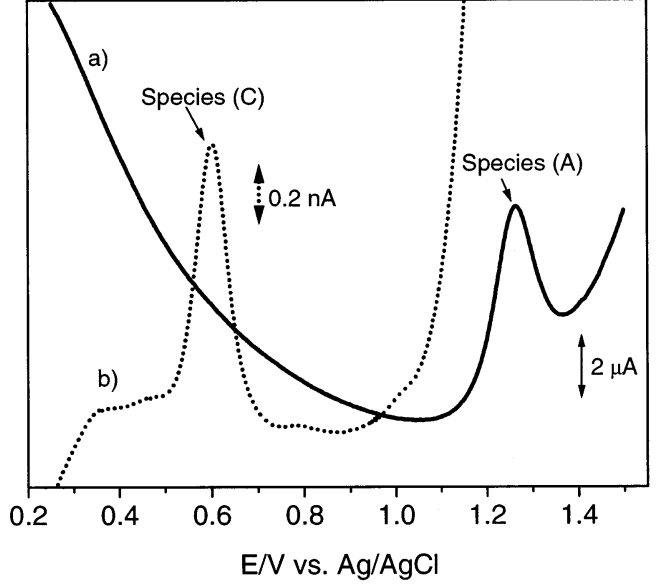

Figure 5. Differential pulse voltammograms of acetanilide: (a) $2.0 \times 10^{-4}$ $\mathrm{M}$ in $0.3 \mathrm{M}$ Britton-Robinson buffer at $\mathrm{pH} 1.9$; (b) $6.8 \times 10^{-2} \mathrm{M}$ in $\mathrm{DCl}$. Scan rate, $5 \mathrm{mV} \mathrm{s}^{-1}$.

Table 2. ${ }^{13} \mathrm{C}$ NMR Data of Acetanilide Deuterated Solutions

\begin{tabular}{cccccc}
\hline & $\begin{array}{c}\text { acetanilide } \\
\left(\mathrm{CD}_{3} \mathrm{OD}+\right.\end{array}$ & $\begin{array}{c}\text { acetanilide } \\
\left(\mathrm{CD}_{3} \mathrm{OD}+\right. \\
\left.\mathrm{D}_{2} \mathrm{O}+\mathrm{DCl}\right)\end{array}$ & $\begin{array}{c}\Delta \delta \\
\left.\mathrm{DCl}\right|^{a}\end{array}$ & $\begin{array}{c}\text { acetanilide } \\
\left(\mathrm{CD}_{3} \mathrm{OD}+\right. \\
\left.\mathrm{D}_{2} \mathrm{O}+\mathrm{NaOD}\right)\end{array}$ & $\begin{array}{c}\Delta \delta \\
\mathrm{NaOD}^{b}\end{array}$ \\
\hline $\mathrm{C}=0$ & 172.6 & 172.9 & +0.3 & 172.8 & +0.2 \\
$\mathrm{C}-1$ & 138.9 & 138.6 & -0.3 & 139.8 & +0.9 \\
$\mathrm{C}-2$ & 121.8 & 122.0 & +0.2 & 122.1 & +0.3 \\
$\mathrm{C}-3$ & 129.8 & 129.8 & 0.0 & 129.9 & +0.1 \\
$\mathrm{C}-4$ & 125.7 & 125.8 & +0.1 & 125.5 & -0.2 \\
$\mathrm{CH}_{3}$ & 23.8 & 23.7 & -0.1 & 24.1 & +0.3
\end{tabular}

${ }^{a} \Delta \delta \mathrm{DCl}=\left(\delta \mathrm{CD}_{3} \mathrm{OD}+\mathrm{D}_{2} \mathrm{O}+\mathrm{DCl}\right)-\left(\delta \mathrm{CD}_{3} \mathrm{OD}+\mathrm{D}_{2} \mathrm{O}\right) \cdot{ }^{b} \Delta \delta \mathrm{NaOD}=$ $\left(\delta \mathrm{CD}_{3} \mathrm{OD}+\mathrm{D}_{2} \mathrm{O}+\mathrm{NaOD}\right)-\left(\delta \mathrm{CD}_{3} \mathrm{OD}+\mathrm{D}_{2} \mathrm{O}\right)$.

Scheme 3. Structure of $\mathrm{N}$-Phenylamide Species (C) Found in DCl

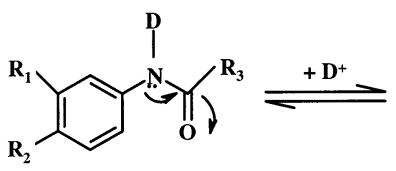

(A)

$\mathrm{R}_{1}=\mathrm{R}_{2}=\mathrm{H} ; \mathrm{R}_{3}=\mathrm{CH}_{3}$ Acetanilide

$\mathrm{R}_{1}=\mathrm{R}_{2}=\mathrm{Cl} ; \mathrm{R}_{3}=\mathrm{CH}_{2} \mathrm{CH}_{3}$ Propanil

solutions, the electrochemistry of acetanilide was also studied. In deuterated acidic solution, acetanilide exhibits a well-defined peak at $+0.6 \mathrm{~V}$ (Figure 5).

To clarify some mechanistic aspects related to the appearance of a new electrochemical signal in deuterated acidic solutions of propanil, it was interesting to check, by NMR spectroscopy, the chemical behavior of acetanilide.

As one can see from the data shown in Table 2, the ${ }^{13} \mathrm{C}$ NMR spectra of acetanilide in neutral and acidic conditions show some differences: a deshielding effect at the carbonyl group $(\Delta \delta=$ $+0.3 \mathrm{ppm})$ and a shielding effect at $\mathrm{C}-1(\Delta \delta=-0.3 \mathrm{ppm})$. It is notable that these effects are more evident for acetanilide than for propanil (although they occur in the same direction). Therefore, the same type of species must be present in these solutions. Even so, the species is more evident for acetanilide than for propanil, which could be related to the pattern of aromatic substitution of these $\mathrm{N}$-phenylamides. The data are in agreement with the electrochemical results and confirm the existence in $\mathrm{N}$-phenylamides of the same type of species in deuterated acidic solutions (Scheme 3).
Under basic conditions, the presence of the negative charge on the amide nitrogen could also be proposed for acetanilide from the ${ }^{13} \mathrm{C} \mathrm{NMR}$ resonance of carbon atoms. After amide deprotonation, there is a deshielding of $\mathrm{C}-1(\Delta \delta=+0.9 \mathrm{ppm})$ and a shielding of the carbon at the para position on the phenyl ring $(\mathrm{C}-4, \Delta \delta=-0.2 \mathrm{ppm})$ (Table 2).

The spectral differences are not so evident as found for propanil due to the absence of the stabilizing effect on the anionic species, which is caused by the inductive field and resonance effects of the halogen atoms and the aromatic nucleus.

In this way, combining electrochemical and NMR data, another reveals that another oxidation process can be proposed for propanil (Scheme 3). NMR studies confirm the presence of species $\mathrm{A}$ and $\mathrm{C}$ in acidic deuterated solutions, with species $\mathrm{C}$ being responsible for the peak at $+0.60 \mathrm{~V}$ upon oxidation of propanil and acetanilide. Nevertheless, formation of species $\mathrm{C}$ is favored in acetanilide due to the absence of $\mathrm{Cl}$ groups on the aromatic ring.

\section{CONCLUSION}

Electrochemical and NMR studies show that protonation of $N$-phenylamides can occur under acidic deuterated conditions, whereas deprotonation of the amide group occurs under basic conditions. In acidic solutions, two oxidation routes can be proposed: one at the nitrogen atom, and the other associated with protonation of the carbonyl group. Due to inductive and field effects, the last route does not proceed to a great extent in nondeuterated aqueous buffer solutions.

The oxidation mechanism of $N$-phenylamides can be followed by electrochemical and spectroscopic methods. The combined data allow one to identify clearly the type of the oxidation species found in solution.

The association of electrochemical and NMR data made the elucidation of the mechanisms of oxidation possible and soon will lead to a better understanding of the (bio)degradation processes of anilide pesticides in the environment.

\section{LITERATURE CITED}

(1) Alawi, M. A. Determination of propanil in rice, potatoes and water by HPLC. Fresenius Z. Anal. Chem. 1982, 312, 536-538.

(2) Tomlin, C. D. S. The Pesticide Manual: A World Compendium, 11th ed.; British Crops Protection Council: London, 1997.

(3) Garrido, E. M.; Lima, J. L. F. C.; Delerue-Matos, C.; Borges, F.; Silva, A. M. S.; Oliveira Brett, A. M. Electrochemical oxidation of propanil and related $N$-substituted amides. Anal. Chim. Acta 2001, 434, 35-41.

(4) Bard, A. J.; Faulkner, L. R. Electrochemical Methods: Fundamentals and Applications, 2nd ed.; John Wiley \& Sons: New York, 2001

(5) Agrawal, P. K.; Schneider H.-J. Deprotonation induced ${ }^{13} \mathrm{C}$ NMR shifts in phenols and flavonoids. Tetrahedron Lett. 1983, 24, 177-180.

(6) March, J. Advanced Organic Chemistry. Reactions, mechanisms and structure, 3rd Ed.; John Wiley \& Sons: New York, 1985.

(7) Brown, R. S.; Bennet, A. J.; Sleboka-Tilk, H. Recent perspectives concerning the mechanism of $\mathrm{H}_{3} \mathrm{O}^{+}$and $\mathrm{OH}^{-}$. Promoted amide hydrolysis. Acc. Chem. Res. 1992, 25, 481-488.

Received for review September 13, 2002. Revised manuscript received November 11, 2002. Accepted November 26, 2002. Fundação para a Ciência e Tecnologia (FCT) is thanked for financial support through Project Praxis/AGR/10184/1998, Research Units R\&D no. 226/94 (F.B.), and PRODEP for a research grant (E.M.G.).

JF025957V 